\section{Experience in Hepatic Transplantation}

By T. E. Starzl with the assistance of C. W. Putnam. Pp. 553, illustrated. Philadelphia, London \& Toronto: W. B. Saunders, 1969. $£ 15$ 19s.

This book is a unique record of a co-ordinated programme of research into liver transplantation, firstly in dogs and then in man.

The one-year survival in this series is $33 \%$, excluding the earlier patients operated on before 1967 and there can be no doubt, on reading this book, that worthwhile survival after liver transplantation is possible. It is written with great clarity and the reader is taken through each stage of the transplantation procedure, starting with selection of the patient and donor to the long-term after-care.

It is essentially a practical book and will be an immense help to workers starting in this field. Each stage in the surgery is clearly illustrated and there are excellent accounts of the anaesthetic management and of the post-operative care. The course of the 25 patients who have received an orthotopic transplant is recorded in detail and no attempt is made to gloss over the complications that have occurred. Instead, the author has tried to analyse exactly what went wrong and how this could be prevented in the future. There is an excellent account of the pathology by Professor $\mathrm{K}$. A. Porter of St Mary's Hospital, where it brings together animal and human data and enables an interesting comparison to be made of the changes found with rejection in man compared with those in the dog and in the pig. Auxiliary transplantation, an operation as yet technically unsatisfactory, is also considered including the problem of competition between the graft and the patient's diseased liver.

It was interesting to read, in view of the controversy in England, of the present views of Starzl and of the Colorado School on the acceptance of irreversible brain injury as the sole criterion of death, despite their earlier doubts.

One cannot recommend this book too highly. To all those interested in transplantation and liver disease, it is a must, and the general reader will also find much of interest.

\section{Recent Advances in Surgery}

Edited by Selwyn Taylor. Seventh edition. Pp. 650, illustrated. London: J. \& A. Churchill, 1969. £4 10s.

This is an excellent book for the busy surgeon who aims to keep abreast of developments in the whole field of surgery.

Organ transplantation and its current status in the surgical and the social spheres is well discussed though it is rather optimistic to hope that it will ever become 'analagous to the treatment of intestinal obstruction as appendicitis'.

New aspects of malignant disease are covered in a chapter on tumours in children, and there is a good section on the management of advanced breast cancer, which can be such a help to patients with terminal illness. A review of gastric carcinoma only serves to emphasise what a common disease this still is, with such an appalling prognosis. Current advances in the understanding of the natural history of melanoma are well set out, though the place of pre-treatment lymphography to demonstrate metastases might have been included.

The range of use of radio-isotopes in surgery is well surveyed, though not all would share the enthusiasm over the practicability of the volumetron. A clear description of the patho-physiology of venous thrombosis is presented, but one feels that more detail of specific vein surgery in the prophylaxis of pulmonary embolism would be welcomc.

The expanding field of gastroenterology has contributions on reflux oesophagitis, gastrin and Crohn's Disease; the chapter on diverticular disease of the colon is headed 'Diverticulosis' and then goes on to say how this term has now been superseded; it also deals with the fascinating actiopathology of the condition and accentuates the meticulous care and attention to detail that the colonic surgeon must possess.

The basis of post-operative metabolic management is elegantly set out and reveals the advances in knowledge of this challengingly labile state. With an increasing number of head injuries passing through our hands either before or after treatment in a neurological centre, a chapter on the short and long term management of these cases is very timely. Finally a section on information retrieval is well written and in the present plethora of scientific papers contains many useful hints on small or large filing systems designed to save hours of fruitless labour: librarians too will find this helpful.

The book contains 24 chapters and 650 clearly presented pages: it seems invidious to point out the several misprints which do alter the sense here and there: the quality of illustration is good, although the photograph on p. 35 could be improved. Overall this is a book which makes valuable reading for all students of surgery from final F.R.C.S. candidates to professors, and it must find a place on the shelf of any self-respecting postgraduate library.

\section{Diagnosis in Orthopaedics}

By LeON Gillis. Pp 312, illustrated. London: Butterworths, 1969. $£ 610 \mathrm{~s}$

The publication of a book devoted to diagnosis alone must be regarded with much interest by orthopaedic surgeons, all the more so as it proves to be the final work of one who has contributed as much to his speciality as did the late Leon Gillis. The author did not survive to see his work reach even proof form, but he would have had no reason, one feels, to be dissatisfied with its final appearance nor with the generous spacing of the text and the clarity of the headings. The illustrations, however, mostly clinical photographs and $\mathrm{X}$-rays, with some line diagrams, are, although well chosen and of good size, not always perfectly reproduced. Additionally, in a book of this size about a subject where appearances are frequently of vital diagnostic value, they could have been more numerous.

The author's approach is slanted unashamedly towards emphasising the importance of physical examination and clinical assessment and this approach is met throughout the chapters on regional orthopaedic disorders as well as in his accounts of bone tumours, vascular deficiency and neuromuscular affections. The evaluation of patients involved in road accidents and subsequent medico-legal problems is also covered. Although the writer follows a system of examination, he handles it flexibly and is quite willing not to be restricted by it when the complexity of the subject matter requires more liberal treatment, as in the diagnosis of back disorders. This means, however, that the book must be viewed as a reference source to be dipped into rather than a text to be read through by a trainee. Indeed at no point does the author seem to claim that he is offering such a book.

Instead, this is a series of personal reflections on the best approach to diagnosis in orthopaedics, well typified by the chapters on 'Gait and Stance' and 'Cerebral Palsy and Muscular Dystrophy'. The book is wide-ranging without being fully comprehensive and at the end of a chapter the reader is left with the impression that he has had a discussion with a wise and experienced colleague whose opinion is to be valued if not invariably accepted.

Unavoidably, technology is playing an increasing part in providing aids and devices to help in the assessment of the orthopaedic patient. Gillis' book is a graceful piece of special pleading that diagnosis in orthopaedics, whilst progressing as a surgical science, should not entirely sacrifice its standing as a clinical art. 